\title{
Transformation of Hotel Food Waste into Animal Feed: Two Operational Periods of the Food for Feed Pilot Unit ${ }^{+}$
}

\author{
Paraskevi Panteli 1,*, Maria Georgiou 1, Nikolaos Stylianidis 1, Eleni Tsiplakou 2, \\ Nadine Paßlack ${ }^{3}$, Katia Lasaridi ${ }^{4}$, Evaggelos Terzis ${ }^{4}$, Chrysoula Bouki ${ }^{5}$, Fani Galliou ${ }^{5}$ and \\ Thrassyvoulos Manios ${ }^{5}$ \\ 1 United Association of Solid Waste Management in Crete, 71202 Heraklion, Crete, Greece; \\ georgiou-m@esdak.gr (M.G.); nstyl@esdak.gr (N.S.) \\ 2 Agricultural University of Athens, 11855 Athens, Greece; eltsiplakou@aua.gr \\ 3 Department of Veterinary Medicine, Freie Universität Berlin, 14195 Berlin, Germany; \\ Nadine.Passlack@fu-berlin.de \\ 4 Harokopio University, 17671 Athens, Greece; klasaridi@hua.gr (K.L.); eterzis57@gmail.com (E.T.) \\ 5 Department of Agriculture, Hellenic Mediterranean University, 71410 Heraklion, Crete, Greece; \\ cbouki@hmu.gr (C.B.); fgalliou@hmu.gr (F.G.); tmanios@hmu.gr (T.M.) \\ * Correspondence: vpanteli@esdak.gr \\ † Presented at the TERRAenVISION 2019, Barcelona, Spain, 2-7 September 2019. \\ Published: 24 March 2020
}

Keywords: food waste; hotels collection system; solar drying; animal feed

Food waste represents 25-35\% of the European Municipal Solid Waste (MSW) [1], thus its diversion into innovative utilization streams is critical for sustainable waste management and the achievement of circularity. Opportunities are even higher in the island of Crete, Greece, where landfilled food waste is 39\% of MSW [2]. In this context, the LIFE-F4F Project implements a pilot scale modified solar drying process that provides an innovative, low-tech and low emissions method for safe transformation of source separated food waste into animal feed. LIFE-F4F targets food waste sourced from the luxury hospitality industry which produces controlled quality food waste due to strict quality assurance standards. The process involves an efficient food waste collection system and a processing unit consisting of a food waste sorting and pulverizing facility and a solar drying greenhouse with two rotary turners, yielding a total nominal processing capacity of $1.5 \mathrm{t} /$ day. Two of the three planned operational periods of the Project were conducted during June-October of 2018 and 2019. During the first period, 4 hotels contributed $150 \mathrm{t}$ of food waste leading to $40 \mathrm{t}$ of feed. The average drying period per 10-day batch at capacity rate loading was 10 days, with material moisture reducing from $70-75 \%$ to a maximum of $12 \%$. Preliminary results from the first period allowed for optimizations, therefore, during the second period, the $170 \mathrm{t}$ of food waste contributed from 5 hotels and one catering company lead to the production of about $60 \mathrm{t}$ of feed. Batch drying period also dropped to 6 days with a moisture reduction from $70-75 \%$ up a maximum of $10 \%$. So far, the end product of the first period has been used in feeding trials with promising preliminary results. Besides the technical success of the conversion process, additional trials are required to assess the safe consumption of the end product by animals, as current legislation prohibits this utilization. Future activities will determine the quality standards required to update legislation towards the safe utilisation of processed food waste products as quality feed for pets, poultry and pigs. Moreover, financial and environmental parameters will be assessed to evaluate the commercial sustainability of 
a life-size application, as well as its impact on waste minimization and utilization as part of an integrated MSW management scheme.

Acknowledgments: This research is funded by EU LIFE15 ENV/GR/0002057: “Food for Feed: An Innovative Process for Transforming Hotels' Food Wastes into Animal Feed".

\section{References}

1. Bidlingmaier, W.; Sidaine, J.-M.; Papadimitriou, E. Separate collection and biological waste treatment in the European Community. Rev. Environ. Sci. Bio/Technol. 2004, 3, 307-320.

2. Gidarakos, E.; Havas, G.; Ntzamilis, P. Municipal solid waste composition determination supporting the integrated solid waste management system in the island of Crete. Waste Manag. 2006, 26, 668-679.

(c) 2020 by the authors. Licensee MDPI, Basel, Switzerland. This article is an open access article distributed under the terms and conditions of the Creative Commons Attribution (CC BY) license (http://creativecommons.org/licenses/by/4.0/). 